\title{
LOS EFECTOS DE LA ACCIÓN DE TUTELA MÁS ALLÁ DE LOS CASOS CONCRETOS. LA PROTECCIÓN DE LOS DERECHOS FUNDAMENTALES EN COLOMBIA
}

\section{THE EFFECTS OF TUTELAGE ACTION BEYOND SPECIFIC CASES. THE PROTECTION OF FUNDAMENTAL RIGHTS IN COLOMBIA}

\section{Natalia BERNAL CANO}

RESUMEN: Este texto es un análisis comparativo acerca de las formas de revisión judicial en Colombia y Europa que protegen los derechos fundamentales en casos concretos. Las formas de objetivación de los procesos individuales para proteger a las personas respecto de las leyes, es el tema especializado más importante en la proposición para incorporar los procesos de revisión judicial con efectos generales en los casos concretos resueltos por la acción de tutela o el proceso directo. Esta proposición es una contribución intelectual para la revisión constitucional en Colombia.

Palabras clave: queja constitucional; revisión judicial; derechos fundamentales.
ABSTRACT: This paper is a comparative analysis about judicial review forms in Colombia and Europe that protect the fundamental rights in concrete cases. "The objectivation" forms of individual process to protect people between the laws is the most important topic specialized in the proposition to incorporate the judicial review process with general effects in the concrets cases resolved by "acción de tutela" o direct process. This proposition is an intellectual contribution for a constitutional review in Colombia.

Descriptors: Constitutional Complaint, Judicial Review, Fundamental Rights. 


\section{INTRODUCCIÓN}

La protección del principio de la supremacía constitucional, como resultado de un examen lógico y objetivo de la compatibilidad normativa, ha sido tradicionalmente la función de la justicia constitucional. Desde que los derechos fundamentales comenzaron a ser el antecedente principal en la actividad de control de constitucionalidad efectuada por las Cortes Constitucionales, el interés concreto de la persona comienza a tener una protección equivalente a la jerarquía de las normas en el ordenamiento jurídico. Varios sistemas de justicia constitucional utilizan como criterio de acceso a la Corte constitucional el interés del individuo para actuar en el proceso constitucional y contemplan la evaluación de la situación subjetiva como un elemento primordial en el procedimiento de control de las normas.

En los recursos individuales, la duda sobre la constitucionalidad de las normas jurídicas en el marco de una demostración de incompatibilidad normativa manifiesta y evidente ha comenzado a perder validez si no se demuestra simultáneamente la amenaza que dicha inconstitucionalidad puede causar en el individuo. A su vez, la lesión ocasionada a la situación particular pierde relevancia jurídica si no se origina en una norma jurídica y si no se presenta procesalmente ante el juez constitucional, una cuestión precisa de constitucionalidad dirigida a solicitar un examen de validez de dicha norma que se estima contraria a los preceptos constitucionales. En este sentido, a la luz de los modelos de justicia constitucional provistos de una gran connotación subjetiva, como los recursos individuales europeos contra los actos de los poderes públicos, una lesión a la situación particular y concreta de un individuo sólo podría tener lugar en la inconstitucionalidad del acto, llámese ese acto sentencia judicial, acto administrativo o ley desprovista de abstracción.

La violación de los derechos fundamentales causada por los actos de los poderes públicos demuestra los efectos verticales de éstos, es decir, solamente cuando dichos actos producen consecuencias nocivas o desfavorables en situaciones particulares, es procedente afirmar que ha existido una vulneración a la esfera subjetiva del individuo, la cual exige corrección directa e inmediata por parte del juez constitucional.

En una relación vertical del individuo frente a los órganos del Estado se derivan entonces diversos efectos de los derechos fundamentales. No 
obstante, en una relación particular donde los sujetos actúan en un plano de igualdad, a diferencia de la anterior relación, puede reclamarse la protección constitucional de los derechos si en dicha relación privada se ha aplicado un acto emanado de los poderes públicos.

Los recursos individuales son una forma híbrida de justicia constitucional cuyo efecto primordial es la corrección del acto jurídico que causa una violación subjetiva. Se parte de la base de que la vulneración del interés concreto tiene su origen en el acto del poder público. Estas líneas tienen por objeto analizar específicamente la protección individual de la situación particular y concreta de un individuo frente a los efectos de aplicación de una ley inconstitucional y el fenómeno de la protección generalizada de los derechos más allá del ámbito de aplicación de la decisión judicial en un caso concreto.

Este tema llama la atención porque en la teoría jurídica del derecho positivo resulta casi imposible demostrar que una ley general y abstracta pueda aplicarse directamente a un individuo y afectarlo sin la presencia de un acto de concretización. En esta situación específica podemos ubicarnos y demostrar que es prioridad del juez constitucional poder subsanar los vicios de las leyes inconstitucionales y a su vez corregir los daños causados por éstas. Podemos descubrir entonces el origen de la vulneración y el recurso individual de origen europeo presenta una solución idónea para corregirla o controlarla antes de la reglamentación o aplicación. Con este remedio se evitarían las múltiples violaciones en situaciones de hecho que se apartan del análisis constitucional de las normas jurídicas.

Analizaremos aspectos fundamentales que no sólo explicarán el fenómeno descrito de corrección de la vulneración objetiva y subjetiva en los recursos individuales, sino igualmente será objeto de análisis la situación atípica de la acción de tutela colombiana como instrumento de protección contra la vulneración que ocurre en situaciones de hecho, sin ser el resultado de la aplicación de un control constitucional. Vale la pena señalar que este recurso de naturaleza subjetiva predominante; comienza a adquirir elementos de control objetivo, acercándose un poco a los recursos individuales contra las leyes, sin que todavía se admita el deber de corrección del ordenamiento jurídico. 
II. LA NATURALEZA MIXTA DE LOS ELEMENTOS ESTRUCTURALES

DE LOS RECURSOS INDIVIDUALES EUROPEOS COMO REMEDIO PROCEDIMENTAL PARA LA PROTECCIÓN FÁCTICA SUBJETIVA Y LA CORRECCIÓN DEL ORDENAMIENTO JURÍDICO

Los recursos individuales en países como Bélgica, Suiza, Alemania, España y Austria, son formas híbridas de justicia constitucional que tienen la finalidad de asegurar la protección de los derechos fundamentales de los individuos que han sido afectados por los efectos de los actos inconstitucionales emanados de los poderes públicos. Se trata de una protección objetiva y subjetiva asegurada contra las sentencias judiciales, actos administrativos y leyes generales desprovistas de cierto grado de abstracción que afectan directamente los derechos fundamentales. Para acceder a la justicia constitucional el individuo debe probar un interés legítimo para actuar; el cual identifica la relación del individuo con un acto del poder público que lo afecta en su situación particular. No existe uniformidad en los sistemas jurídicos citados para determinar la legitimación del demandante en el proceso ya que ésta bien puede consistir en la existencia de una violación de derechos fundamentales o simplemente en la lesión o amenaza de un interés concreto.

\section{El elemento subjetivo del interés para actuar en los recursos individuales}

El interés que debe justificar el recurrente para solicitar el control de constitucionalidad de un acto que lo afecta en su situación particular, puede consistir en que dicho acto sea aplicable a la situación concreta de una persona y que exista el riesgo cierto, directo, personal, inmediato y actual de desmedro, como sucede en el sistema constitucional belga, en el cual los individuos instauran un recurso cuyo objeto es anular directamente las leyes inconstitucionales. Puede definirse el concepto de interés como la motivación particular de una persona en acudir a la jurisdicción constitucional con el objeto de obtener la protección de los derechos fundamentales. 
El profesor Otto Pfersmann considera que la violación de situaciones específicas por una norma general debe ser inmediata en el tiempo y directa sin la intervención de un acto de concretización. ${ }^{1}$

El artículo 142, línea 3 de la Constitución belga, estipula claramente que "toda persona que justifique un interés puede acudir a la Corte constitucional". Esta disposición enuncia que antes de proceder al examen de fondo del litigio, el juez debe verificar "la consistance du lien qui existe entre la personne requérante et la norme attaquée". ${ }^{2}$ La relación entre el actor constitucional y la ley inconstitucional habilita al individuo a solicitar constitucionalmente ante la Corte la protección de los derechos. Esta noción de interés ${ }^{3}$ se aparta de la acción pública de inconstitucionalidad colombiana, reconocida en derecho comparado bajo el nombre de

1 Pfersmann, Otto, "Le recours direct entre protection juridique et constitutionnalité objective”, Cahiers du Conseil Constitutionnel, núm. 10, pp. 6-10. Sobre el tema existe un trabajo de investigación doctoral iniciado en noviembre de 2004 y próximo a sustentar en la Universidad de Paris 1 Panthéon-Sorbonne, el cual elaboré siendo discípula del profesor Pfersmann Otto, "Le contrôle abstrait de constitutionnalité de la loi sur recours d'un individu en Allemagne, Bélgique et Colombie". La tesis desarrolla el tema de la protección individual contra los efectos de las leyes inconstitucionales, el tema de la función objetiva de los recursos individuales, el acceso a la Corte Constitucional, la fusión de elementos de los controles abstracto y concreto; presenta un control mixto de constitucionalidad para la protección de la Constitución y de los derechos fundamentales y se elaboró con la colaboración académica de los siguientes organismos: Cour Constitutionnelle de Belgique, Corte Constitucional Colombiana, École Doctorale de Droit Comparé, Université de Paris 1 Panthéon-Sorbonne, Deutche Hoch Shüle für Verwaltungs Wissenschafter, Benjamín N. Cardozo School of Law, Yeshiva University, New York, Ludwing Maximilians Universität von München.

2 Delperee, Francis y Rasson-Roland, Anne, La Cour d'Arbitrage, Bélgica, Larcier, 1996, p. 53.

3 La exigencia del interés ha sido criticada por un sector de la doctrina belga : " $L$ ' $e$ xigence d'intérêt appliquée à la justice constitutionnelle peut avoir des effets pervers: plus la norme sera générale et abstraite moins il sera possible de faire preuve d'un intérêt suffisamment individualisé pour être recevable à introduire un recours. La Cour d'arbitrage a bien perçu le danger et apprécie de manière particulièrement large ce rapport individualisé ; Ainsi, en matière de droit de vote et d'éligibilité, elle a considéré que tout électeur ou tout candidat a un intérêt à demander l'annulation des dispositions de la dite loi électorale susceptibles d'affecter défavorablement son vote ou sa candidature et que dans un système démocratique les électeurs sont indirectement concernés par les conditions que doivent remplir les mandataires élus", Delgrange, Xavier, "La Cour d'arbitrage et le citoyen", Regards croisés sur la Cour d'Arbitrage, Bruselas, Bruylant, 1995, p. 242. 
actio popularis, pues se considera nocivo el objeto indeterminado o impreciso del debate constitucional que se instaura para examinar la compatibilidad formal o material de leyes a la Constitución al igual que los efectos que provocan la obstrucción de la justicia por la multiplicidad de acciones instauradas.

El interés para actuar en los recursos individuales es la protección individual deseada por el actor con relación a la ley que afecta su situación específica. Este presupuesto depende siempre de la relación entre el actor y la ley sometida a control de constitucionalidad.

Según un sector de la doctrina belga, el elemento objetivo del recurso de nulidad parece incompatible con la noción de interés. Si la ley es más general y abstracta, será más difícil probar un daño a la situación de un individuo. El interés debe ser concreto y este elemento se deriva de las normas cercanas a las situaciones específicas. El interés es a su vez un criterio interno de filtro que permite seleccionar los casos en que la situación del actor se encuentra realmente afectada.

La persona natural o jurídica debe probar el perjuicio causado por la ley inconstitucional en su situación particular para poder acceder a la justicia y en esto radica el carácter subjetivo del recurso mixto contra las leyes en el sistema belga, cuyos lineamientos estructurales constituyen una de las iniciativas para reformar el control abstracto de constitucionalidad y la acción de tutela en Colombia.

El grado de vulneración causada por la ley, al ser un elemento subjetivo determina en el contencioso belga la procedibilidad del control objetivo de la norma y la posibilidad de anularla. En el caso de comprobar la inconstitucionalidad derivada de una incompatibilidad entre la ley y la Constitución, los efectos de la nulidad pueden favorecer los destinatarios de la ley en el sentido de que cese la vulneración causada directamente a los derechos.

En Alemania, la queja individual directa contra las leyes inconstitucionales puede instaurarse ante la Corte constitucional por los individuos que afirman ser lesionados en sus derechos fundamentales. Este recurso directo de protección individual no exige al recurrente agotar las vías judiciales previas que impone el principio de subsidiariedad, como excepción prevista en el marco del artículo 90 de la Ley sobre la Corte Constitucional, con el fin de impedir al recurrente o actor un perjuicio irremediable. El recurso contra la ley se admite por lo general en el Tri- 
bunal Constitucional cuando el objeto de debate constituye una materia de interés público. Se trata de una manifestación excepcional de la queja individual contra los actos de los poderes públicos, sin configurar una tipología independiente de control de constitucionalidad. El propósito de la figura procesal es la corrección de la vulneración de los derechos fundamentales afectados gravemente por las leyes inconstitucionales, a partir de casos concretos. Estas controversias particulares pueden transformarse en temas de interés público y suscitar la atención de la Corte constitucional sin necesidad de agotar previamente los mecanismos jurisdiccionales para corregir la vulneración. Estamos ante una manifestación mixta de justicia constitucional donde la protección del orden jurídico objetivo resulta de la protección subjetiva y específica del individuo.

En Bélgica el recurso de nulidad contra las leyes inconstitucionales previsto en el artículo primero de la ley especial del 6 de enero de 1989 sobre la Cour d'Arbitrage, actualmente, denominada Corte Constitucional, es una categoría híbrida de control de constitucionalidad que permite la relación estrecha entre la protección individual y el control objetivo de las leyes. Algo similar podría adoptarse en Colombia si se acepta la fusión del control abstracto con el elemento subjetivo de la acción de tutela en un contencioso mixto, como una iniciativa de reforma constitucional para fortalecer la protección directa de los derechos.

En Colombia existe una forma de justicia constitucional atípica cuyo objeto fundamental es la protección subjetiva de cualquier persona en situaciones fácticas que afectan los derechos fundamentales. A diferencia de los recursos individuales contra las leyes citados anteriormente, la acción de tutela consagrada en el artículo 86 de la Constitución presenta restricciones estructurales para controlar la constitucionalidad de una ley que afecta directamente a un individuo. Igualmente, no se realiza control de constitucionalidad de los actos administrativos. Se trata de un procedimiento individual que busca corregir la vulneración subjetiva causada por la acción u omisión de los poderes públicos o por los particulares, en eventos en los cuales la víctima de la vulneración se encuentra en circunstancias de indefensión o subordinación, o cuando se afectan los derechos en ejecución de un servicio público, y en el evento en que se desea proteger un interés colectivo. Aunque el análisis del acto legal inconstitucional no hace parte del proceso iniciado por acción de tutela, sí puede hablarse de la incorporación de algunos elementos derivados del 
control objetivo de las normas jurídicas que tienen que ver con la protección individual más allá del caso concreto.

\section{La función objetiva de los recursos individuales, el efecto general de educación o la corrección del ordenamiento jurídico objetivo}

Los recursos constitucionales directos contra los actos de los poderes públicos han adquirido una fisonomía más objetiva porque los efectos de las decisiones constitucionales van más allá de los límites de los litigios individuales, para perfeccionar, corregir o interpretar el orden jurídico positivo.

En España doctrinalmente se habla de "objetivación del recurso de amparo constitucional", cuando se analiza particularmente el fenómeno del amparo contra leyes inconstitucionales. ${ }^{4}$

En este tema la doctrina no es unánime ya que varios autores como Diez Picazo se apartan de la procedencia del recurso como fórmula de protección objetiva de los derechos fundamentales, mientras que otros como Carmen Blasco consideran que la esfera objetiva de los derechos es indisoluble de la subjetiva y para lograr la protección procede el amparo contra leyes.

En amparo contra leyes es una buena fórmula de protección que emerge directamente del recurso individual español, la controversia existente radica en establecer si se trata de una fórmula novedosa del procedimiento de amparo o si se trata de un control indirecto de la ley a iniciativa del juzgador cuando el actor sugiere el control del acto administrativo y de la ley reglamentada o si existe en realidad un procedimiento distinto con autonomía propia.

Puede afirmarse que el amparo contra leyes es una figura procesal equivalente al recurso de nulidad contra las leyes inconstitucionales en Bélgica, cuya naturaleza es mixta en razón de la coexistencia de elementos subjetivos y objetivos en el contencioso. Sin embargo no puede admitirse que se trata de un control abstracto, pues esta modalidad de justicia constitucional es eminentemente objetiva. Si puede afirmarse que el con-

4 Blasco Soto, Carmen, "El recurso de amparo contra leyes en España", Revista de Derecho, vol. XII, agosto de 2001, pp. 157-177. La autora analiza el procedimiento como un "proceso complejo y deficiente, por no haber alcanzado el fin que debe perseguir: esto es, la protección de esos derechos frente a las violaciones del legislador". 
trol abstracto pueda evolucionar, transformando su esencia en la fórmula del amparo contra leyes. En este caso hablaríamos de un contencioso mixto donde la prioridad del juez es proteger a la persona directamente de los vicios del ordenamiento jurídico.

Se trata entonces de otro procedimiento autónomo donde necesariamente se protege a la persona de los efectos de los actos desprovistos de concretización. Esta fórmula presentaría la ventaja de la descongestión judicial, por cuanto la reclamación subjetiva se uniría al control objetivo de la ley antes de un desarrollo legal por vía del reglamento. De esta manera, podría evitarse la vulneración masiva de derechos fundamentales antes de la aplicación del acto de concretización.

El control integral de la ley inconstitucional que vulnera un derecho es la vía más idónea de protección subjetiva, pues evita las múltiples demandas ante diversas jurisdicciones como resultado de una vulneración homogénea de múltiples derechos individuales cuyo origen es la inconstitucionalidad de la ley.

En España, la figura del amparo contra leyes surge según un sector de la doctrina de la "autocuestión de inconstitucionalidad" consagrada en el artículo 55.2 de la Ley Orgánica sobre el Tribunal Constitucional. Al respecto se ha manifestado que este precepto facilita a los ciudadanos el acceso al Tribunal Constitucional para que se declare la inconstitucionalidad de una ley. No podríamos decir que se trata exactamente de un fenómeno de actio popularis como sucede en Colombia, porque la figura de la autocuestión de inconstitucionalidad tiene el objeto de amparar al individuo contra los efectos de una ley inconstitucional; esta finalidad existe sin duda alguna en los recursos individuales como el caso belga o el alemán con lo que se descarta el modelo estrictamente objetivo cuyo fin es determinar la compatibilidad estructural o material de una ley con respecto a la Constitución.

El recurso directo contra las leyes se encuentra previsto en el artículo 144 de la Constitución austríaca, en el artículo 93.1.4 de la Constitución alemana y 90.1 de la Ley sobre el Tribunal Constitucional. En Suiza se contempla tácitamente la figura en el artículo 113.I.3.

En España, el amparo contra leyes carece de apoyo legislativo específico, por ello existen tantas divergencias en la interpretación. No existe regulación directa que derive de la Constitución o de la ley y los límites son impuestos a nivel jurisprudencial. 
La jurisprudencia constitucional del Tribunal Constitucional español reconoce el amparo indirecto o mediato contra la ley, cuando el acto administrativo que afecta a un individuo tiene su causa directa en la inconstitucionalidad de la ley. Al respecto, la profesora Cármen Blasco Soto desarrolla una evolución jurisprudencial en su artículo "El recurso de amparo contra leyes en España".5

"El amparo contra leyes no es una acción directa del ciudadano frente a la norma", bien lo ha establecido así la doctrina española. ${ }^{6}$ La doctrina y la jurisprudencia alemana consideran que la decisión del juez constitucional no resuelve únicamente un caso particular ni protege de manera exclusiva los derechos subjetivos del recurrente, sino que tiene igualmente una función suplementaria; "un efecto general de educación". Además de la protección individual, el recurso constitucional puede defi-

5 Así, en la sentencia 41/198120, de 18 de diciembre, resolvió: "Una interpretación racional de este precepto (artículo 55.2 LOTC) obliga a entender que la inconstitucionalidad de la ley que lesiona derechos fundamentales y libertades públicas puede ser alegada por el recurrente de amparo. De este modo puede admitirse una pretensión directa de constitucionalidad sostenida por los particulares...". 21. No obstante, la jurisprudencia de nuestro Tribunal Constirucional ha sido oscilante y desconcertante. Sirva como ejemplo la STC 291/2000 de 30 de noviembre, FJ 7o., donde se destaca: "Conviene señalar que el hecho de que el recargo al que se está haciendo referencia venga establecido en una norma con rango de ley no impide que este Tribunal pueda examinar sus actos de aplicación y a través de ellos analizar si el precepto legal que ha sido aplicado respeta los derechos fundamentales que consagra la Constitución. Una cosa es que a través del recurso de amparo no se pueda pretender la declaración de inconstitucionalidad de normas con rango de ley, como viene insistiendo este Tribunal, "la vía del recurso de amparo no es la adecuada para la impugnación directa de las Leyes" (SSTC 206/1990, de 17 de diciembre [RTC 1990/206], F. 5; 119/1991, de 3 de junio [RTC 1991/119], F. 4; 31/1994, de 31 de enero [RTC 1994/31], F. 4; 120/1998, de 15 de junio [RTC 1998/120], F. 1), y otra muy distinta es que a través de este recurso no podamos pronunciarnos sobre la posible inconstitucionalidad de la ley aplicada en los casos en los que la lesión de derechos fundamentales que se imputa al acto impugnado traiga causa directa de la ley de la que ese acto es aplicación. Esta posibilidad, además, se encuentra específicamente prevista en el artículo 55.2 LOTC". Véase Blasco Soto, Cármen, op. cit., nota 4, pp. 157-177.

6 Calamandrei, P., "Ilegitimidad constitucional de las leyes en el proceso civil", Derecho procesal civil. Instituciones de derecho procesal, Buenos Aires, 1962, t. III, p. 69. Véase también en este sentido pero desde otra óptica Figueruelo Burrieza, A., "Algunos problemas que suscita la autocuestión de inconstitucionalidad (artículo 55.2 de la LOTC)", REDC, núm. 21, 1987, p. 242; Urias Martínez, J. P., La cuestión interna de inconstitucionalidad, Madrid, 1996, pp. 13 y ss. 
nirse como un medio específico para la protección, interpretación y perfeccionamiento del orden constitucional objetivo. ${ }^{7}$

Estas apreciaciones son compartidas por el profesor Hans Grupp, quien considera que "el hecho de que la Ley Fundamental ponga a disposición del ciudadano, para la protección de los derechos fundamentales contra el poder público, el medio jurídico del recurso constitucional tiene un efecto educativo (Edukationseffekt) considerable".

En Alemania, la decisión constitucional puede resolver los eventuales problemas de derecho constitucional con ocasión de una interpretación obligatoria que se impone de manera general en el marco restringido de un recurso individual. Este elemento objetivo puede aparecer aunque la Corte Constitucional declare que la ley susceptible de examen no vulneró los derechos fundamentales explícitamente mencionados por el actor. ${ }^{8}$ En Bélgica, la técnica de interpretación conforme a la Constitución, ${ }^{9}$ al igual que las medidas correctivas introducidas en la actividad legislativa a través de recomendaciones, ${ }^{10}$ constituyen igualmente medios protecto-

7 Rec 33,247,258 y ss., Rec 45, 63,74, véase igualmente Schlaich, Klaus, "Procédures et techniques de protection des droits fondamentaux. Tribunal Constitutionnel Fédéral Allemand", Actes du II Colloque d'Aix-en Provence, febrero de 1981, pp. 19-21, "Cours constitutionnelles européennes et droits fondamentaux", Collection Droit Public Positif, Economica-Presses Universitaires d'Aix Marseille, 1987, p. 109.

8 'Il n'en va pas moins que le $99 \%$ de procédures 'non couronnées de succès' 'protègent', également les droits fondamentaux même lorsque les décisions intervenues de ce chef constatent qu'il n' y a pas, en l'espèce (in casu), violation d'un droit de ce type. Abstraction faite de la considération qui précède, la procédure du recours constitutionnel ne répond pas simplement au but de nature subjective que constitue la protection des droits fondamentaux du citoyen face à la puissance publique: comme toutes les procédures se déroulant devant le Tribunal constitutionnel fédéral, elle a également un but objectif, qui est l'éclaircissement des problèmes de droit constitutionnel par l'interprétation de la Loi Fondamentale. Envisagée sous cet angle, la décision rejetant comme non fondé au recours constitutionnel assure elle-même la 'protection' des droits fondamentaux". Rupp, Hans G., "Objet et portée de la protection des droits fondamentaux. Tribunal Constitutionnel Fédéral Allemand", Actes du II Colloque d'Aix-en-Provence, fébrero de 1981, pp. 19-21. "Cours constitutionnelles européennes et droits fondamentaux", Collection Droit Public Positif, Economica-Presses Universitaires d'Aix- Marseille, 1987, p. 242.

9 Lombaert, Bruno, "Les techniques d'Arrêt de la Cour d'arbitrage", Revue Belge de Droit Constitutionnel, 1996, pp. 317-355.

10 Behrendt, Christian, "Quelques réflexions sur l'activité du juge constitutionnel comme législateur-cadre", Revue de la Faculté de Droit de l'Université de Liège, 2006, 
res del ordenamiento jurídico objetivo en el marco del recurso individual de nulidad de leyes inconstitucionales.

La perfección del ordenamiento jurídico y la unificación de criterios jurisprudenciales relativos a la lógica estructural y material de las disposiciones legislativas no es incompatible con la protección de intereses subjetivos en el control de constitucionalidad.

En consecuencia, la coexistencia de técnicas propias de los controles concreto y abstracto en el marco de un procedimiento único es una prueba materializada de las funciones del juez constitucional como protector de la jerarquía normativa y garante de los derechos y libertades fundamentales. ${ }^{11}$

La protección de la supremacía de la Constitución es una de las misiones del control de constitucionalidad, independientemente de su carácter concreto o abstracto. En este sentido, el juez constitucional verifica el respeto de la jerarquía normativa y las normas contrarias o incompatibles con la Norma Suprema son declaradas nulas. ${ }^{12}$

I-2, pp. 9-24. Del mismo autor, "Le juge constitutionnel comme législateur cadre positif: les normes juridictionnelles relatives à la production et au contenu de normes législatives futures. Une analyse comparative en droit français, belge et allemand", Bruyllant Bruxelles, 2006.

11 Renauld, Bernadette, "La Cour d'Arbitrage depuis 2003: confirmation de compétences, nouveautés de procédure", La Cour d'Arbitrage: un juge comme les autres?. Actas del coloquio organizado por la Facultad de Derecho de la Universidad de Liège y la Conferencia Libre de Jeune Barreau de Liège el 28 mayo de 2004, Jeune Barreau de Liège, 2004. pp. 27-53. Véase también Martens, Paul, "Le métier de juge constitutionnel", La saisine du juge constitutionnel, aspects de droit comparé, Francis Delperee et Pierre Foucher (dir.), Bruselas, Bruylant, 1998, pp. 25-43. Véase también en la misma obra Anne Rasson-Roland, "Le recours des particuliers auprès de la Cour d'arbitrage", pp. 163-173.

12 "Dans la Verfassungsgerichtsbarkeit, l'organe auquel est confiée l'annulation des lois inconstitutionnelles n'exerce pas à proprement parler une véritable fonction juridictionnelle, bien qu'il ait, par l'indépendance de ses membres, l'organisation d'un tribunal. A partir de la différence que Kelsen considère décisive entre la fonction juridictionnelle et la fonction législative (tandis que cette dernière crée des normes générales, la première ne fait que créer des normes individuelles), le maître de l'école de Vienne résout le problème du sens de l'annulation d'une loi décidée par le Tribunal. 'En appliquant la Constitution à un fait concret de production législative, et en arrivant à annuler des lois inconstitutionnelles', soutiendra Kelsen, le Tribunal constitutionnel n'établit pas une norme générale mais l'annule, c'est- à- dire qu'il émet l'actus contrarius correspondant à la production juridique, autrement dit, il agit en qualité de 'législateur négatif'. En définiti- 
El recurso directo de los particulares contra las leyes en Suiza, Bélgica, Austria y en Alemania, ${ }^{13}$ posee en parte la misma misión objetiva. En efecto, el juez constitucional realiza el control de la conformidad de una ley o de un acto en aplicación de la ley (acto administrativo o decisión judicial) con relación a la Constitución, pero esta función es igualmente esencial que la protección individual de los derechos subjetivos; ${ }^{14}$ por estas razones, el recurso individual posee una doble finalidad. La doctrina alemana ha considerado en este aspecto:

Die Funktion der Verfassungsbeschwerde erschöpft sich nicht im individuellen Grundrechtsschutz, sie hat auch die Funktion das objecktive Verfassungsrecht zu wahren und seiner Auslegung und Forbildung zu dienen... Insoweit kann die Verfassungsbeschwerde zugleich als spezifisches Rechtsschutzmittel des objectiven Verfassungsrechts bezeichnet werden. ${ }^{15}$

La función de la queja individual constitucional no se agota en la protección de los derechos individuales, ella tiene igualmente la función de preservar el derecho constitucional objetivo y de servir a su interpretación y perfeccionamiento. En este sentido se puede reconocer la queja individual

ve, la décision du Tribunal d'annuler une loi a le même caractère qu'une loi abrogeant une autre norme légale. C'est un acte de législation négative"; Fernandez Segado, Francisco, "La faillite de la bipolarité 'modèle américain-modèle européen' en tant que critère analytique du contrôle de la constitutionnalité et la recherche d'une nouvelle typologie explicative", Mélanges en l'honneur de Franck Moderne. Mouvement du droit public, Dalloz, 2004, p. 1092; Kelsen, H., Wer soll der Huter der Verfassung sein?, Véase también el texto traducido al español por R. J. Brie, “¿Quién debe ser el defensor de la Constitución?”, Madrid, Tecnos, 1995, pp. 36 y 37.

13 Véanse las sentencias de la Corte Constitucional Alemana: "Garantie objective du droit constitutionnel”: E 2,79,(86), E 1,372 (379,414), E 24,299 (300), E 4,193 (198), E 9,1 (2), 120 (121). Véase en materia de procesos de objetivación de intereses de defensa legal, Lipphardt, Die Gleichheit der politischen Parteien vor der öffentlichen Gewalt, 1975, pp. 474 y ss; véase también Häberle, Peter, "El derecho procesal constitucional como derecho constitucional concretizado frente a la judicatura del Tribunal constitucional", Nueve ensayos constitucionales y una leccion jubilar, Lima, APDC, 2004, pp. 40 y 41.

14 "The FCC examines the formal as well as the substantive compatibility of the statute with the Constitution". Michalowski, Sabine, "The Protection of Civil Liberties", German Constitutional Law, Dartmouth Publishing Company Limited, 1999, p. 42.

15 Korrioth, Stéphane, Das BverfG, München, pp. 140 y 141. 
constitucional, como medio específico de protección de los derechos subjetivos, al igual que de los derechos constitucionales objetivos. ${ }^{16}$

El razonamiento de las cortes constitucionales en Bélgica y Alemania posee actualmente nuevas características porque el control de constitucionalidad es el resultado de la articulación o mezcla de dos elementos fundamentales: se trata de la introducción de técnicas de protección objetiva del ordenamiento y de manifestaciones de protección subjetiva de individuos en circunstancias particulares y concretas. En este aspecto, la llamada "objetivación de los recursos individuales" es un fenómeno interesante comentado por la literatura jurídica que muestra un carácter más general del litigio individual a partir del análisis de los efectos de la decisión judicial. En este caso específico, el análisis de la constitucionalidad de las leyes puede sobrepasar los límites estrechos del caso particular.

El grado de abstracción de un procedimiento constitucional, particularmente a propósito del examen del acto normativo objetivo analizado, puede ser más o menos pronunciado. En efecto, la técnica de protección constitucional empleada por las cortes constitucionales puede ser más o menos abstracta o más o menos concreta según la pertinencia de la situación específica del actor en el razonamiento judicial. Este elemento subjetivo puede ser esencial en el comienzo del procedimiento o en la fase del razonamiento.

Los elementos del control concreto de constitucionalidad aparecen en los procedimientos abstractos cuando el juez constitucional analiza particularmente los efectos de aplicación de las leyes y los actos de concretización de normas abstractas, esta situación ya ha sucedido en Colombia cuando la Corte Constitucional en la sentencia C-038 de 2006 concedió efectos retroactivos a la declaratoria de constitucionalidad con el fin de

16 "Par la voie du recours constitutionnel, l'individu doit pouvoir faire respecter en dehors des possibilités de protection juridique par les différents ordres de juridiction ses droits fondamentaux et ainsi participer au 'combat pour le droit dans le domaine du Droit Constitutionnel. La fonction du recours ne s'épuise donc nullement dans la protection individuelle des droits fondamentaux. Il s'agit par ailleurs d'un moyen de protection juridique du droit constitutionnel objectif qu'il lui revient ainsi de garantir, comme de servir son interprétation et son développement. En tant que le citoyen défend sa sphère de droits fondamentaux; il enclenche en même temps une procédure qui sert également le droit constitutionnel objectif", Dittmann, Armin, "Le recours constitutionnel en droit allemand", trad. de Otto Pfersmann, Cahiers du Conseil Constitutionnel, núm. 10, octubre de 2000-febrero de 2001. 
corregir la vulneración de los derechos patrimoniales de los contribuyentes afectados con el cobro de tributos inconstitucionales mediante la exigencia de devolución del dinero recaudado. Otro de los casos más típicos de la fusión es el efecto de la declaración de inconstitucionalidad de la disposición legal que prohibía el acceso a la pensión de sobrevivientes del cónyuge fallecido, a las viudas que contrajeran segundas nupcias o establecieran uniones maritales de hecho. En este caso, no sólo se declara la inconstitucionalidad de la norma demandada, sino que se ordena el pago de la pensión a quienes fueron afectadas por la ley contraria a la Constitución.

En la sentencia C-421 de 2006 de la Corte Constitucional Colombiana, la situación específica del actor o recurrente es pertinente en el marco del control objetivo de la ley y la decisión constitucional se concretiza a través de una orden de carácter obligatorio. Los argumentos de la acción muestran en este caso una situación de carencia legislativa, producida por la derogación de una disposición que preveía la organización de los concursos públicos de notarios. En razón de la ausencia de regulación producida por dicha derogación, el derecho a la igualdad de diversos notarios que pretendían acceder a los cargos públicos fue desconocido. Se subraya que esta sentencia va más lejos que la actividad de confrontación de la compatibilidad normativa porque el juez busca concretizar directamente los fines constitucionales. Se realiza el control objetivo y se aplica una medida de protección subjetiva. Se trata de una orden específica dirigida al Consejo Superior de Notarios, dirigida a realizar los concursos correspondientes. Esta orden protege las situaciones individuales y concretas de los individuos afectados en su derecho a la igualdad. Un alcance similar poseen las órdenes dictadas como efecto de las sentencias proferidas en los procedimientos de naturaleza subjetiva predominante iniciados por acción de tutela.

Los efectos de la omisión legislativa son asumidos por el juez constitucional a través de la aplicación directa de la Constitución. En este aspecto, con el fin de concretizar los fines constitucionales y de proteger los derechos de los notarios, el poder del juez en el control abstracto iniciado por actio popularis, permite imponer una orden obligatoria a una entidad pública. Debe subrayarse que el proceso objetivo se concretiza y uno de los efectos de la decisión concierne una situación particular. Se trata de la discriminación de candidatos al cargo de notario. Con el fin de 
corregir la vulneración de los derechos fundamentales, el proceso abstracto permite en este caso específico la inclusión de medidas aplicables en recursos individuales.

La Corte Constitucional Colombiana ha reconocido explícitamente los efectos concretos de las decisiones proferidas en procesos de control abstracto iniciado por actio popularis, en los casos análogos de grave amenaza de los derechos fundamentales. En este aspecto, si los efectos de la inconstitucionalidad de la ley afectan una diversidad de intereses subjetivos homogéneos, el juez constitucional se permite aplicar medidas propias del control concreto en un procedimiento de control abstracto. Podemos analizar, por ejemplo, la situación particular de los propietarios de viviendas financiadas por sistemas de crédito UPAC. ${ }^{17}$

En la práctica, varios particulares fueron afectados por los intereses del crédito destinado a programas de vivienda que aumentaban progresivamente generando dificultades significativas para el pago. En este caso, la medida resulta excesiva por cuanto no se beneficia al deudor en el ámbito de un buen plan de vivienda, sino que se crea una situación demasiado gravosa para él. En este caso específico, la vulneración subjetiva tiene lugar como efecto de la aplicación de un sistema legal inconstitucional que no prevé sistemas de control para prevenir los perjuicios a nivel socio-económico.

La Corte Constitucional en sus sentencias C-383 de 1999 y C-700 de 1999 examina elementos empíricos como factor adicional a las leyes y determina la vulneración patrimonial de diversas personas. Se subraya en este caso la vulneración de una diversidad de situaciones concretas. El interés general derivado de las situaciones de hecho que acompañan el debate incita al juez constitucional a concretizar su decisión y a corregir las imperfecciones de la ley.

La sentencia C- 1489 de 2000 relata una serie de precedentes en los cuales fue importante en el razonamiento constitucional poder definir el efecto causado por la ley inconstitucional en las situaciones concretas, además del análisis estructural o material de la ley.

En 2001, Constance Grewe ${ }^{18}$ demuestra con algunos ejemplos precisos la superposición de las técnicas de protección objetiva y subjetiva en

17 UPAC: Unidad de Poder Adquisitivo Constante.

18 Grewe, Constance, "A propos de la diversité de la justice constitutionnelle en Europe: L'enchevêtrement des contentieux et des procédures", Les droits individuels et le 
el marco de la jurisprudencia de la Corte Constitucional alemana. En este aspecto, el desplazamiento de la justicia constitucional "del control de la ley hacia la protección de los derechos" muestra el lugar predominante de los derechos fundamentales y los debates doctrinales en curso sobre la adopción de un nuevo modelo de justicia constitucional.

Con el fin de garantizar a los individuos una protección efectiva en los casos concretos y cumplir los propósitos generales de preservación del orden jurídico objetivo, los jueces constitucionales pueden evitar la congestión judicial y los desequilibrios manifiestos del contencioso, asegurando simultáneamente a los individuos una protección de carácter homogéneo en los casos similares. Esta armonía entre el interés general, el buen funcionamiento de la justicia y los intereses particulares, puede asegurarse a través de la incorporación o la aplicación combinada de ciertas medidas de protección de carácter objetivo o subjetivo, que surgen de la jurisprudencia comparada en diferentes tipos de proceso constitucional. Las medidas o los criterios de protección establecidos por las cortes constitucionales son manifestaciones del carácter abstracto o concreto del control de constitucionalidad.

\section{LA CONNOTACIÓN SUBJETIVA DE LA ACCIÓN DE TUTELA Y EL RECONOCIMIENTO DE UNA FUNCIÓN OBJETIVA EN LA JURISPRUDENCIA CONSTITUCIONAL COLOMBIANA}

La acción de tutela consagrada constitucionalmente en el artículo 86 de la Constitución y desarrollada por el Decreto 2591 de 1991 muestra claramente el carácter eminentemente subjetivo del objeto del procedimiento. Sin embargo, el contencioso constitucional adquiere elementos objetivos un poco relacionados con el control abstracto donde se evidencia que los efectos de las sentencias proferidas cobijan situaciones fácticas similares más allá del litigio, con el propósito de asegurar el interés general del Estado en la protección de los derechos.

De esta manera no sólo se analiza la protección subjetiva individual, sino se evitan las futuras violaciones en casos análogos.

juge en Europe. Mélanges en l'honneur de Michel Fromont, Presses Universitaires de Strasbourg, 2001, pp. 255-266. 


\section{Hacia un criterio analítico de la función objetiva de la acción de tutela}

En la jurisprudencia constitucional colombiana no existía hasta febrero de 2008 un criterio analítico para denominar el alcance de las órdenes de la acción de tutela más allá del caso concreto, las cuales se adoptan en general para proferir programas o planes dirigidos a ampliar la cobertura y fortalecer el ámbito de protección de los derechos. Este fenómeno en el cual surgen órdenes que imponen la carga de dictar medidas de alcance general para prevenir la vulneración futura de los derechos, aunque no es propio de los recursos individuales europeos, sí puede relacionarse con uno de sus efectos, o al menos aproximarse poco a poco a él. Se trata del efecto objetivo como medida de corrección y protección del ordenamiento jurídico.

En la teoría alemana los derechos fundamentales tienen una connotación subjetiva y a la vez son elementos objetivos del ordenamiento jurídico; se necesita un mecanismo con ese doble carácter tendente a asegurar no sólo la protección individual sino la coherencia en el orden jurídico objetivo. Si bien la protección de la norma constituye un interés general del Estado, también es un interés general la protección de los derechos como institución normativa o como elementos del ordenamiento jurídico.

He denominado a las "técnicas de objetivación del contencioso", ${ }^{19} \mathrm{me}$ didas de protección de carácter objetivo, siendo éstas empleadas por el juez constitucional como manifestaciones del control abstracto de constitucionalidad que ligan los casos concretos a la protección de la validez del ordenamiento jurídico.

Cuando el juez constitucional superpone las técnicas de protección del orden jurídico objetivo y las medidas de protección individual a partir de cada caso concreto, las finalidades de la justicia constitucional serán me-

19 Las técnicas de objetivación del contencioso pueden ser definidas como "des moyens employés par la jurisprudence constitutionnelle, destinés à ne pas détacher les demandes basées sur des intérêts concrets, de l'intérêt général et de la défense de la légalité dans chaque procès constitutionnel particulier". Peter Häberle cita la tesis de Konrad Hesse sobre la objetivación de contenido constitucional. Entrevista realizada a Peter Häberle, "El derecho procesal constitucional como derecho constitucional concreto frente a la judicatura del tribunal constitucional", Pensamiento Constitucional, año VIII, núm. 8, Lima, 2002, pp. 23-59. 
jor garantizadas; no sólo se protege la situación individual sino que se evita la vulneración en casos sucesivos homogéneos. Igualmente, cuando el juez constitucional fortalece la protección subjetiva en el control abstracto de normas jurídicas, la acumulación de múltiples quejas o recursos individuales homogéneos, en el caso colombiano (acciones de tutela), podría evitarse. Se trata entonces de una especial fórmula para evitar la congestión de los despachos judiciales.

La técnica de incorporación de medidas de depuración del derecho objetivo en los recursos individuales belga y alemán facilita la protección generalizada y homogénea de situaciones individuales y concretas. Igualmente, la unificación de criterios de corrección del orden jurídico evita los desequilibrios del contencioso ocasionados por la proliferación de recursos individuales provistos del mismo objeto: anular la producción legislativa defectuosa a partir del examen de casos concretos.

Al igual que las razones formales anteriormente explicadas, la congestión de las cortes constitucionales se debe a la acumulación masiva de recursos individuales, generalmente instaurados por la misma causa o razón de fondo: ciertos defectos intrínsecos de la ley que violan los derechos fundamentales en múltiples situaciones particulares homogéneas. En este caso, las fórmulas o reglas de razonamiento, propias del control abstracto empleadas de manera reiterada por las cortes constitucionales - como el examen de medidas legislativas proporcionales a los fines constitucionalmente legítimos, o el análisis integral de constitucionalidad, o el control del grado mínimo de protección de la ley respecto a los derechos fundamentales - pueden incitar al legislador a corregir integralmente su producción normativa y evitar de esta manera los daños ulteriores a las situaciones individuales. Estas fórmulas pueden a su vez asegurar el equilibrio en el acceso a la Corte Constitucional por que el individuo estará obligado a formular estrictamente una cuestión de constitucionalidad conforme a las líneas jurisprudenciales uniformes de interpretación del orden jurídico objetivo. De esta forma el recurrente podrá acudir a la jurisdicción gracias a la uniformidad de condiciones de procedibilidad de los recursos y el proceso constitucional podrá comenzar respetando la unidad de exigencias constitucionales previstas para admitir los argumentos del actor.

De otra parte, para no ceñirnos exclusivamente a líneas jurisprudenciales reiteradas que pre-determinen el acceso a la Corte, el actor puede 
elevar cuestiones o formular controversias que permitan la evolución y el perfeccionamiento del derecho constitucional.

Podemos encontrar una manifestación de la objetivación del contencioso constitucional, en la etapa de selección o admisión de recursos individuales. Generalmente la importancia de la materia debatida o el interés público que se suscita en dicha materia constituye un criterio objetivo para admitir el recurso individual. De esta manera un litigio o caso concreto no se revisa por la Corte Constitucional, si se trata de una controversia intrascendente que sólo interesa a las partes procesales. En efecto, es necesario que la vulneración cause un impacto significativo, de tal forma que se justifique iniciar un debate constitucional de trascendencia pública o interés general. La Corte Constitucional en Alemania trabaja de manera muy similiar a la Corte Suprema de los Estados Unidos, al prohijar una técnica cercana a la de write of certiorari para darle especial trascendencia al debate que se origina en una situación particular. El procedimiento de admisión de quejas individuales en Alemania (Anhamenverfahren), dispone como criterios de admisión la importancia de la vulneración, la importancia del tema para el derecho constitucional además de la trascendencia pública. Al respecto ha habido una serie de críticas doctrinales que consideran que este elemento objetivo altera la esencia subjetiva y la fisonomía del recurso contra los actos de los poderes públicos.

En España, un debate de similar naturaleza ha surgido con ocasión de la aplicación del llamado amparo contra leyes. Respecto a las iniciativas para controlar el acceso al Tribunal Constitucional y solucionar los problemas de congestión, se plantea la posibilidad de restringir los presupuestos procesales. Incluso a nivel doctrinal se rechazan los casos en que la lesión provocada al derecho fundamental tiene poca relevancia. Cruz Villalon, quien defiende esta postura, manifiesta que se trata de una propuesta de aproximación a la jurisdicción constitucional alemana. En este sentido se analiza si la vulneración del derecho fundamental amerita ser conocida por el Tribunal Constitucional. ${ }^{20}$

En Colombia, respecto a los procedimientos iniciados por acción de tutela, no hay criterios objetivos de selección, ya que el juez es discrecio-

20 Cruz Villalón, "El recurso de amparo constitucional: el juez y el legislador", Los procesos constitucionales. Segundo Simposio de Derecho Constitucional. Cuadernos y Debates, núm. 41, Centro de Estudios Constitucionales de Madrid, 1992. 
nal en decidir la revisión del caso. El recurso de protección subjetiva no procede para determinar la constitucionalidad de una ley ni para proteger la persona de dicha inconstitucionalidad. Sin embargo, en aplicación de políticas generales de protección de los derechos, el juez constitucional puede ligar los casos concretos al interés general de protección de los elementos normativos del orden jurídico objetivo.

Una fórmula de objetivar el recurso concreto consiste en ampliar el impacto de sus efectos. Nos preguntamos cómo podría el juez constitucional emitir una decisión que trascienda el caso concreto.

\section{Los efectos de la acción de tutela en casos análogos relacionados}

con políticas públicas y con el interés general del juez constitucional en la protección de los derechos

Para el desarrollo de este tema es importante referirnos de manera específica a las controversias que suscitan un interés público o que se encuentran relacionadas con alguna política pública. Para estos efectos, el juez constitucional puede adoptar una decisión en procedimientos iniciados por acción de tutela con efectos que superan la órbita restringida del litigio. En este caso, se trata de ampliar la cobertura de la protección del derecho constitucional que ha resultado afectado en una circunstancia particular. Al no existir control de constitucionalidad de las normas, aspecto que podría modificarse como una iniciativa de reforma constitucional en Colombia, la violación en circunstancias de hecho puede examinarse con fines preventivos con miras a proteger individuos que podrían muy seguramente resultar afectados de manera análoga. Así sucedió en la sentencia T-165 de febrero 21 de 2008, cuando la Corte Constitucional, utilizando por primera vez la noción objetiva de la acción de tutela, ampara no sólo el derecho de una persona afectada por la omisión de un particular que se niega a suministrar información relativa a un procedimiento cosmetológico, sino que a fin de evitar la vulneración sucesiva de varios derechos en circunstancias análogas, protege la salud pública, comunicando al organismo de vigilancia y control de medicamentos (INVIMA) que es procedente su intervención técnica para descifrar los componentes del producto cosmetológico no identificado aplicado a la tutelante en el procedimiento referido. La tutela de los derechos fundamentales a la información y a la salud es concedida para amparar una víctima de daños físicos en un procedimiento estético. Aunque el efecto objetivo es reco- 
nocido en otros ordenamientos jurídicos donde existen los recursos individuales contra las leyes, la acción de tutela colombiana no tiene fines de corrección del ordenamiento jurídico. Se emplea el término funcional para determinar la protección de derechos fundamentales en casos semejantes.

La acción de tutela colombiana, a diferencia de otros recursos individuales, como Alemania, presenta aún restricciones en lo relativo al amparo directo contra leyes. La decisión teóricamente no puede producir efectos generales. Sin embargo, se extienden los efectos de la acción cuando se busca amparar circunstancias análogas a aquélla donde ha tenido lugar la lesión subjetiva.

Debe tratarse de circunstancias análogas previsibles en las cuales otras personas puedan resultar perjudicadas. Debe existir igualmente un riesgo de daño grave para extender los efectos de la decisión. Dicho riesgo no puede ser remoto o eventual. El daño no puede ser irrisorio, sino que debe tratarse de un daño grave que pueda ocurrir de manera sucesiva y uniforme. En estos casos se resalta el interés especial del juez constitucional para proteger los derechos fundamentales en su esfera subjetiva y objetiva. Por esto, son procedentes las medidas que trascienden a las partes en el proceso.

La acción de tutela frente a este tipo de casos no sólo tiene un objeto curativo de la vulneración específica, sino que posee un fin preventivo de la violación futura. Para este caso específico la corte constitucional reconoce el efecto objetivo de la acción de tutela, sin admitir aún que por tratarse de un recurso individual, cabría de manera inequívoca la corrección del ordenamiento jurídico como consecuencia de los efectos de aplicación de leyes inconstitucionales.

Como un control a la repetición de la vulneración, el juez de tutela puede impartir orden a prevención según lo autoriza el artículo 24 del Decreto 2591 de 1991. Entonces podemos afirmar que se reconoce de manera exclusiva la función objetiva de la acción de tutela cuando se requiere la protección de intereses semejantes, independientemente de la violación subjetiva causada. Faltaría ampliar un poco más dichos efectos con miras a que sean generales, admitiendo la procedencia del control de normas generales y abstractas dentro del ámbito del mismo proceso. Así, la acción de tutela tendría un alcance muy similar a los recursos individuales, cuya naturaleza es mixta. En el caso de que existan tesis adversas 
tendentes a defender el carácter subjetivo de la tutela como solución de amparo a los derechos fundamentales desprovista de control normativo, debe considerarse entonces un nuevo modelo procesal, de naturaleza mixta equivalente al recurso individual directo contra las leyes.

Cuando se asocia el interés concreto del actor a las prioridades del juez en la protección de intereses generales, es posible extender los efectos de la decisión proferida en el caso concreto. De esta manera puede afirmarse que existiría un recurso más objetivo para proteger como institución los derechos consagrados en el orden jurídico positivo.

La función objetiva de la acción de tutela no se había reconocido de manera explícita por la jurisprudencia constitucional colombiana, hasta el caso donde se examinó el amparo de los derechos fundamentales de la víctima de una lesión dermatológica en un procedimiento cosmetológico. No se había dado hasta ahora ese paso como sí ha sucedido antes en la jurisprudencia de otros tribunales constitucionales. Aunque el alcance de la función objetiva no es la misma, en Colombia sí procede dicho efecto cuando se trata de proteger casos similares al concreto examinado, y en estos eventos pueden expedirse diversas modalidades de órdenes, cuyo efecto no es sólo específico. Con el propósito de garantizar el amparo de los derechos fundamentales en su esfera objetiva, las órdenes de tutela pueden llegar a tener un alcance más general cuando se pretende proteger a varias personas en casos similares, cuando, se ha ordenado a algún organismo la inspección, la vigilancia o el control en temas de trascendencia pública o de interés general, con miras a prevenir la vulneración sucesiva de los derechos o simplemente, el alcance de la orden consiste en ordenar la realización o ejecución de planes, políticas o programas que puedan promover la sumisión de los poderes públicos a los derechos fundamentales.

Podemos citar por ejemplo, la sentencia T-595 de 2002 en materia de acceso de discapacitados físicos al servicio público de transporte, donde no sólo se protege a las partes del litigio en la controversia planteada. Pensando en el interés general de facilitar el transporte público terrestre de todos los discapacitados en general, se definió el carácter prestacional del derecho de locomoción sin justificar la inacción continuada del Estado en los eventos en que no se diseñan políticas, planes o programas per- 
tinentes. La política de integración social es abarcada en el conflicto particular a pesar de tener relación directa con el interés general. ${ }^{21}$

En la sentencia número T-087 de 2005, se protegió la libertad de movimiento de los menores "de brazos" en medios de transporte terrestre. La Corte Constitucional emitió una orden para ejecutar una política general consistente en que se garantice el acceso al transporte público y se divulgue un manual del usuario.

En la sentencia SU 225 de 1998 se amparó a los menores con fines preventivos de los efectos de la enfermedad de meningitis bacteriana que pudieran atentar contra el derecho a la salud y se exige a las autoridades sanitarias organizar programas de prevención con miras a amparar a la población infantil en riesgo.

La política estatal de protección del menor fue entonces analizada en un litigio particular; de esta manera el recurso individual adquiere elementos objetivos del control abstracto de constitucionalidad al amparar intereses generales que se encuentran contemplados en normas jurídicas.

Resulta importante citar los avances respecto a la declaración de efectos inter comunis, caso en el cual la Corte Constitucional Colombiana busca extender la protección reconocida en el caso concreto a circunstancias similares, en las cuales diversas personas o grupos de personas con intereses constitucionales homogéneos puedan resultar afectadas o se encuentran vulneradas de manera análoga y la llamada "declaración de Estado de cosas inconstitucionales para proteger los derechos fundamentales vulnerados o amenazados de manera masiva", como ha ocurrido con la población desplazada por la violencia. Al respecto vale la pena citar las consideraciones jurisprudenciales más importantes introducidas por la sentencia de tutela T-025 de 2004 y el estudio profundo del investigador mexicano Julián Tole Martínez, titulado "La teoría de la doble dimensión de los derechos fundamentales en Colombia. El estado de cosas inconstitucionales, un ejemplo de su aplicación", publicado en la revista Cuestiones Constitucionales, núm. 15, julio-diciembre de 2006.

21 Se resolvió “Ordenar a Transmilenio S. A. que en el término máximo de dos años, a partir de la notificación de la presente, diseñe un plan orientado a garantizar el acceso del accionante al sistema de transporte público básico de Bogotá, sin tener que soportar limitaciones que supongan cargas excesivas, y que una vez diseñado el plan inicie, inmediatamente, el proceso de ejecución de conformidad con el cronograma incluido en él”. 
Las formas de justicia constitucional nos muestran recursos individuales con efectos más allá de los casos concretos, para proteger intereses generales en controversias de trascendencia pública y sistemas de control abstracto u objetivo con efectos en la situación concreta de un individuo afectado por la aplicación directa de una ley en su situación específica. El resultado de esta fusión será sin duda un nuevo sistema de protección constitucional del ordenamiento jurídico y de los intereses subjetivos del individuo reconocidos por el derecho positivo. El nuevo esquema se adapta poco a poco por vía jurisprudencial; falta adaptar las instituciones a los cambios actuales y reconocer estos avances en el marco jurídico de una reforma constitucional. 